\title{
Hereditary angioedema due to C1 - inhibitor deficiency in Switzerland: clinical characteristics and therapeutic modalities within a cohort study
}

\author{
Urs C. Steiner ${ }^{1 *}$, Christina Weber-Chrysochoou², Arthur Helbling ${ }^{3}$, Kathrin Scherer ${ }^{4}$,
}

Peter Schmid Grendelmeier ${ }^{2}$ and Walter A. Wuillemin ${ }^{5}$

\begin{abstract}
Background: Registration of trigger factors, prodromal symptoms, swelling localization, therapeutic behavior and gender-specific differences of the largest cohort of patients with hereditary angioedema due to C1-Inhibitor deficiency (C1-INH-HAE) in Switzerland.

Methods: Questionnaire survey within a cohort study: Consenting eligible patients with diagnosed HAE according to clinical history, physical examination and laboratory results, including plasma values for C1-INH and C4 were selected. To each participant we sent a questionnaire assessing patients' birthday, sex, date of first symptoms and diagnosis, trigger factors, prodromal symptoms, frequency and localization of angioedema, medication use and co-morbidities. Clinical information was collected in each center and then transmitted to the cohort database. Frequencies and distributions were summarized. Associations between gender and trigger factors or prodromal symptoms or localization of angioedema were assessed in multivariate analyses correcting for patients' age.

Results: Of 135 patients, data from 104 patients (77\%) were available for analysis. Fifty- four percent were female, mean age at diagnosis was 19.5 years (SD 14.1), Mean age when completing the questionnaire was 44.0 (SD 19.8). More women than men were symptomatic (44/57 vs. 36/47; $p=0.005)$. This association remained when correcting for age at diagnosis (16.10.95\% Cl (5.17 to 26.70); $p=0.004)$. Swelling episodes ranged between 1 and 136 episodes/year. Swelling was more common among female than among male $(-13.15$ (95 \% Cl; -23.10 to -3.22$), p=0.010)$. Age at diagnosis was inversely associated with the total number of attacks $0.50(-0.88$ to -.011$) ; p=0.012)$. One third of patients were on danazol prophylaxis.

Conclusion: We found large differences of HAE in male and female both in terms of symptom number and swelling episodes. Women are more affected by intensity and frequency of angioedema episodes than men. Danazol treatment remains widely used as effective prophylaxis despite its side effects. New therapies which selectively influence the hormonal estrogen balance could open new therapeutic options mainly for women and maybe also for men.
\end{abstract}

Keywords: Hereditary Angioedema (HAE), Gender related clinical characteristics, Danazol, Individualized therapy

\footnotetext{
*Correspondence: Urs.Steiner@usz.ch

'Division of Clinical Immunology, University Hospital Zurich, Zurich,

Switzerland

Full list of author information is available at the end of the article
} 


\section{Background}

Hereditary angioedema with $\mathrm{C} 1$ inhibitor deficiency (C1INH-HAE) is a rare, inherited disease, clinically characterized by recurrent acute swelling episodes on the extremities, abdomen, face, trunk, or airways, resulting from increased vascular permeability. These episodes occur spontaneously or are triggered by stimuli such as trauma, psychological stress, or infections. The swellings in HAE patients are highly variable in terms of trigger factors, severity, frequency and location [1,2].

There are two types of C1-INH-HAE: Type I with decreased secretion of $\mathrm{C} 1$ inhibitor protein and Type II with secretion of a dysfunctional protein $[3,4]$. Both result from an aberration in the gene coding for the plasma protein C1-inhibitor (C1-INH). Another type of HAE with normal C1-INH protein was first described in 1985. In some of these patients a mutation in F12 gene can be detected and they are classified FXII-HAE, the other patients without detection of a genetic defect are classified unknown HAE (U-HAE) [3-5]. According to several nationwide cohort studies the prevalence of $\mathrm{HAE}$ is estimated to be between 1:50000 and 1:100000 [6-9]. In Switzerland three studies describing the clinical characteristics of patients with HAE have been published so far [10-12]. Switzerland with approximately 8 million inhabitants is divided in four different language regions. The German part with about $70 \%$ inhabitants, the French part (23\%), Italian part (6\%) and Rumantsch part $(1 \%)$. The present study is based on 135 patients living in the German part. Based on the estimated prevalence, the number of patients in our Swiss cohort corresponds to approximately $85 \%$ of all HAE-affected patients living in Switzerland and thus represents the most complete set.

It is known that women suffer from more frequent and more severe angioedema attacks than men [13]. In this study, expanding on previous research, [13] we analyzed gender specific differences of HAE in more detail comparing trigger factors, prodromal symptoms, swelling localization and therapeutic behavior on women and men. Finally, we discuss treatment plans for different disease manifestations.

\section{Methods}

The protocol of this study received Ethics approval and was conducted according to the principles of good clinical practice and strictly adhered to the ethical standards outlined in the Declaration of Helsinki [14].

\section{Identification of patients}

Patients from the Division of Haematology of the Cantonal Hospital Lucerne, the Allergy Units of the University Hospitals from Zurich, Berne and Basel were included. All patients fulfilling the diagnostic guidelines criteria for $\operatorname{HAE}[3,15]$ qualified for inclusion. All included patients gave their written informed consent. Patients from the French and Italian part of Switzerland were excluded because Ethics approval for this study was missing.

\section{Data collection}

HAE was diagnosed on the basis of patient history, clinical examination and laboratory results, including plasma levels of functional C1-INH, antigenic C1-INH and complement factor C4. C1-INH-HAE type I was diagnosed when $\mathrm{C} 4$ was decreased and functional and antigenic C1-INH levels were below $50 \%$ of normal. C1INH HAE type II was diagnosed when $\mathrm{C} 4$ was decreased, functional C1-INH was below $50 \%$ and antigenic C1-INH was above $50 \%$ of normal. In 2013 a detailed questionnaire was sent to the participants, assessing the patients' birthday, sex, date of first symptoms and diagnosis, trigger factors, prodromal symptoms, frequency and localization of angioedema, medication use and comorbidities. Patients answered the questions retrospectively for the year 2012. Specific additional clinical information was collected in a survey conducted in 2013 and 2014 via direct contact with the patient, the family physician, hospitals, or relatives. Because ethical approvals for detailed questionnaire of the centers of Zürich and Basel were not available, a closing evaluation of all data was possible for 104 patients of the centers Lucerne and Berne.

\section{Data handling}

Clinical information was collected in each center and then transmitted to the administration site of the Swiss HAE cohort (Haematology of the Cantonal Hospital Lucerne). The information collected in the survey was screened and checked for plausibility by one researcher and then added to the electronic database. The cohort database is maintained by one researcher. If data were implausible or incomplete we contacted the patient or his / her caregiver for clarification. The final dataset was then pseudonymised and prepared for analysis. The pseudonymisation key is stored at the administration site.

\section{Statistical analysis}

We summarized variates with means and standard deviations or percentages where appropriate. Associations between female gender and presence of prodromal symptoms (yes/no) were assessed in multivariate analyses correcting for patients' age. The association between overall number of attacks and attacks on the abdomen were assessed using mixed linear models entering an indicator variate for the patient id as random factor. Also, we assessed whether the age at diagnosis 
was associated with the reported number of attacks. Analyses were performed using the Stata 14.1 statistics software package. (StataCorp. 2015. Stata Statistical Software: Release 14. College Station, TX: StataCorp LP.).

\section{Results}

The analysis was based on 104 consenting patients (57 women and 47 men) with a mean age of 44.0 years (SD 19.8) who completed the questionnaire referring to 2012. Hundred and two patients were affected by C1INH-HAE type I, 2 by type II.

The mean age at symptom onset was 11 years (SD 8.2). In men it was 9 years (SD 9.2) three years earlier than in women with 12 years (SD 7.6). For details please see Table 1 . The average delay from the first symptoms until diagnosis in patients without a family history of the disease was 14 years (SD 11) for both women and men.

\section{Frequency and localization of angioedema}

The gender-related frequency of angioedema is shown in Table 2 . Women had more symptoms than men (45/57 vs. $33 / 47 ; p=0.005)$ also when correcting for age at diagnosis $(16.10$. 95\%CI (5.17 to 26.70$) ; p=0.004)$. Only 12

Table 1 Characteristics of 104 patients completing the questionnaire

\begin{tabular}{|c|c|}
\hline Parameter & Frequency / mean (SD) \\
\hline women / men & $57 / 47$ \\
\hline mean age (years) & 44 (SD 19.8; range 5 - 80) \\
\hline mean age women (years) & 44 (SD 19.8; range 13 - 80) \\
\hline mean age men (years) & 41 (SD 19.7; range $5-72)$ ) \\
\hline \multicolumn{2}{|l|}{ age groups } \\
\hline$\leq 10$ years & 3 \\
\hline $11-20$ years & 12 \\
\hline $21-30$ years & 17 \\
\hline $31-40$ years & 14 \\
\hline $41-50$ years & 18 \\
\hline $51-60$ years & 21 \\
\hline$\geq 60$ years & 19 \\
\hline \multicolumn{2}{|l|}{ symptom onset } \\
\hline mean age symptom onset & $11(S D$ 8.2) \\
\hline mean age symptom onset women & $12(S D 7.6)$ \\
\hline mean age symptom onset men & 9 (SD 9.2) \\
\hline delay of diagnosis ${ }^{\mathrm{a}}$ & $14(\mathrm{SD} 10.9)$ \\
\hline delay of diagnosis ${ }^{\mathrm{a}}$ women & $\mathrm{n}=37: 14(\mathrm{SD} 10.3)$ \\
\hline delay of diagnosis ${ }^{\mathrm{a}}$ men & $n=21: 14(S D 12.3)$ \\
\hline \multicolumn{2}{|l|}{ HAE variants } \\
\hline Type I & 102 \\
\hline Type ॥ & 2 \\
\hline
\end{tabular}

affected people with unknown family history $n$ number
Table 2 Gender-related number of attacks of angioedema for 2012

\begin{tabular}{|c|c|c|c|c|}
\hline & Total & Women & Men & \\
\hline Patients & 104 & 57 & 47 & \\
\hline symptomatic patients $^{\mathrm{a}}$ & 78 & 45 & 33 & $p=0.563$ \\
\hline number of angioedema attacks & 1770 & 1290 & 480 & $p=0.015$ \\
\hline$\geq 1 /$ week $^{\mathrm{b}}$ & 10 & 8 & 2 & \\
\hline$\leq 1 /$ week $_{i} \geq 1 /$ month $^{c}$ & 30 & 22 & 8 & \\
\hline$\leq 1 /$ month $\geq 1 /$ year $^{d}$ & 38 & 15 & 23 & \\
\hline
\end{tabular}

aSymptomatic: all patients who experienced angioedema in 2012; asymptomatic: all patients who didn't experience angioedema in 2012 ${ }^{b}$ frequent number of attacks

cintermediate number of attacks

$d_{\text {rare number of attacks }}$

female and 14 male patients reported to be symptom free in the preceding year. Swelling episodes ranged between 1 and 136 episodes/year and was more common among female than among male $(-13.15$ (95 \% CI; -23.10 to -3.22$), p=0.010)$. The localizations of angioedema occurred is shown in Table 3. Overall, attacks occurred most often on the abdomen ( $43 \%$ cases), followed by the extremities, cerebral angioedema (headache), trunk, genitals, face and larynx. Age at diagnosis was inversely associated with the total number of attacks $0.50(-0.88$ to -.011$) ; p=0.012$ ).

\section{Prodromal symptoms and trigger factors}

Prodromal symptoms like fatigue, nausea, skin erythema, local paresthesia or itching, which may precede angioedema were reported by $51 \%$ of women and $43 \%$ of men $(p=0.397)$.

Eighty-one percent of female and $66 \%$ of male respondents stated that trigger factors preceded angioedema attacks (Table 4).

Table 3 Gender-related localization and number of angioedema in 2012

\begin{tabular}{llllll}
\hline & women (57) & & & men (47) \\
\cline { 2 - 3 } \cline { 5 - 6 } & $\mathrm{n}$ of patients & $\mathrm{n}$ of AE & & $\mathrm{n}$ of patients & $\mathrm{n}$ of AE \\
\hline abdomen & $40(70 . \%)$ & 575 & & $28(59 . \%)$ & 191 \\
extremities & $34(60 \%)$ & 312 & & $27(57 . \%)$ & 118 \\
headache & $11(19 \%)$ & 186 & $5(11 \%)$ & 43 \\
trunk & $15(26 . \%)$ & 89 & & $7(15 \%)$ & 37 \\
genitals & $11(19 \%)$ & 70 & & $11(23 . \%)$ & 35 \\
face & $14(24 . \%)$ & 41 & & $8(17 \%)$ & 33 \\
larynx & $9(16 \%)$ & 17 & $7(15 \%)$ & 23 \\
\hline $\begin{array}{l}\text { Percentages are related in women to the total amount of women, in men to } \\
\text { the total amount of men }\end{array}$ \\
$\begin{array}{l}n \text { number } \\
\text { AE Angioedema }\end{array}$
\end{tabular}


Table 4 Trigger factors

\begin{tabular}{llll}
\hline Trigger factor & Number of patients & women & men \\
\hline All & 77 & 46 & 31 \\
Emotions & 53 & $33(72 \%)$ & $20(64 \%)$ \\
Trauma / Mechanical trigger & 47 & $27(59 \%)$ & $20(64 \%)$ \\
Foodstuff / allergies & 33 & $20(43 \%)$ & $13(42 \%)$ \\
Infection & 21 & $13(28 \%)$ & $8(26 \%)$ \\
Hormones & 35 & $34(74 \%)$ & $1(3 \%)$ \\
None & 27 & $11(24 \%)$ & $16(57 \%)$
\end{tabular}

Percentages relate to the total of women or men who noticed trigger factors

\section{Therapy}

In Switzerland danazol and tranexamic acid (TA) are used for prophylactic treatment, whereas plasma - derived $\mathrm{C} 1$-Inhibitor (pd $\mathrm{C} 1-\mathrm{INH}$ ) and Icatibant are administered for treatment of acute attacks. Some patients practice individual replacement therapy (IRT), which means that they administer pd $\mathrm{C} 1$-INH on demand very early when prodromal symptoms appear before an acute angioedema attack [16].

One third of patients were on prophylaxis. Danazol was used by $23 \%$ of women and $27 \%$ of men at doses of $100 \mathrm{mg}$ twice a week to $200 \mathrm{mg}$ daily. TA was taken by $10 \%$ of women and $8 \%$ of men with daily doses from $500 \mathrm{mg}$ to $4000 \mathrm{mg}$. IRT was practiced by 7 women and 2 men.

In the event of an acute attack pd C1INH was administered to $56 \%$ of women and $53 \%$ of men, whereas $16 \%$ of women and $6 \%$ of men administered Icatibant. (Table 5).

The frequency of angioedema episodes in 2012 with or without prophylaxis/IRT is shown in Table 6. Without prophylaxis, women suffered from 835 angioedema episodes (22/woman) and men from 216 (7/man). Women on danazol experienced 143 attacks (11/woman) and men on danazol 64 (5/man). Six women and 4 men using danazol had no attacks during the study period. Comparing gender-related localization of angioedema when on prophylactic treatment with danazol, women suffered from fewer symptoms on all locations, with the

Table 5 Therapeutic modalities in $2012(n=104)$

\begin{tabular}{llll}
\hline Pharmacological prophylaxis & women and men & women & men \\
\hline tranexamic acid & 10 & $6(10 \%)$ & $4(8 \%)$ \\
danazol & 26 & $13(23 \%)$ & $13(27 \%$ \\
IRT & & & \\
pd C1 - INH & 9 & $7(12 \%)$ & $2(4 \%)$ \\
Therapy of acute attacks & & & \\
Icatibant & 12 & $9(16 \%)$ & $3(6 \%)$ \\
pd C1 - INH & 57 & $32(56 \%)$ & $25(53 \%)$ \\
\hline
\end{tabular}

Percentages are related in women to the total amount of women, in men to the total amount of men exception of the trunk, face and brain (headache) (Table 7).

Among the patients on TA, one woman and one man were asymptomatic, one man suffered from frequent attacks ( $\geq 1$ /week) one man and two women from intermediate attacks $(\leq 1 /$ week; $\geq 1 /$ month), and three women and one man from rare attacks $(\leq 1 /$ month; $\geq 1 /$ year $)$. Two women on IRT suffered from frequent attacks, four women and one man from intermediate, and one each from rare attacks.

Three different forms of treatment were practiced: Oral (Danazol, TA), intravenous (pd C1 INH), and subcutaneous (Icatibant). C1INH home therapy was practiced by 23 women and 15 men. The family doctor performed the therapy for 10 women and 5 men. Hospital treatment was required for 8 women and 4 men. Of the 30 patients who experience more than 1 attack/ month, 16 were able to administer C1INH on their own at home. Two hundred and forty-eight swelling episodes were not treated by 21 women and 16 men.

\section{Comorbidities}

The patients were asked about their medication intake other than HAE-related drugs. Specific medication allowed conclusion to be drawn about the diagnosis of other diseases than HAE. Thirty-two per cent, (20 women and 13 men) were affected by comorbidities (Table 8). Arterial hypertension was the most frequent disorder with $22 \%$ (14 women, 9 men) followed by dyslipidemia at $5.7 \%$ (5 women, 1 man). Patients with danazol-prophylaxis suffered with $54 \%$ (9 women, 5 men) from more comorbidities compared to the $24 \%$ (11 women, 8 men) without danazol prophylaxis.

\section{Discussion}

In this study we described the gender-related clinical and therapeutic characteristics of the great majority of Swiss HAE patients. Women were more affected by intensity and frequency of angioedema episodes than men, which is in line with a previous report [13]. This is most probably related to the exogenous and endogenous estrogen in puberty, ovulation during the menstrual cycle, estrogen-based birth control pills, or estrogen replacement therapy [17].

\section{Prodromal symptoms and trigger factors}

About half of the patients, mainly women, noticed prodromal symptoms once in their lives. This awareness to perceive oncoming attacks enables the patients to start therapy early, which in turn leads to a quicker treatment response [18].

The proportion of patients reporting the perception of trigger factors corroborates the data recently described by Zotter and colleagues [19]. Mental stress, mechanical 
Table 6 Frequency of attacks with or without prophylaxis / IRT in 2012

\begin{tabular}{|c|c|c|c|c|c|c|c|c|}
\hline & & & & \multicolumn{5}{|c|}{ Number of Angioedema attacks } \\
\hline & & & & no attacks & $\geq 1 /$ week $^{a}$ & $\geq 1 /$ month $^{\prime} \leq 1 /$ week $^{b}$ & $\geq 1 /$ year $\leq 1 /$ month $^{c}$ & Total $n$ of $A E$ \\
\hline \multicolumn{3}{|c|}{ Women and men } & 104 & 26 & 10 & 30 & 38 & 1770 \\
\hline \multirow[t]{5}{*}{ Women } & All & & 57 & 12 & 8 & 22 & 15 & 1290 \\
\hline & prophylaxis & None & 38 & 5 & 7 & 18 & 8 & 835 \\
\hline & & Danazol & 13 & 6 & 1 & 2 & 4 & 143 \\
\hline & & TA & 6 & 1 & 0 & 2 & 3 & 48 \\
\hline & IRT & $\mathrm{C} 1-\mathrm{INH}$ & 7 & 0 & 2 & 4 & 1 & 264 \\
\hline \multirow[t]{5}{*}{ men } & All & & 47 & 14 & 2 & 8 & 23 & 480 \\
\hline & prophylaxis & None & 30 & 9 & 1 & 5 & 15 & 216 \\
\hline & & Danazol & 13 & 4 & 0 & 2 & 7 & 64 \\
\hline & & TA & 4 & 1 & 1 & 1 & 1 & 78 \\
\hline & IRT & $\mathrm{C} 1-\mathrm{INH}$ & 2 & 0 & 0 & 1 & 1 & 122 \\
\hline
\end{tabular}

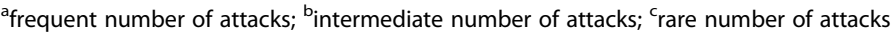

$n$ number, $A E$ Angioedema

no attacks: asymptomatic for the year 2012

trauma and physical exertions are the most relevant trigger factors for both genders, followed by food and infections. Foodstuff as a trigger factor is also described by Zotter et al. If it is intolerance or allergy which induces angioedema has to be elucidated in further studies. In our study, a large variety of different foodstuff was reported, including milk products, fruit, seafood and nuts. Endogenous or exogenous estrogen is an exclusive and the most important trigger factor for women. Female were more prone to mental stress than men, physical and mechanical exertion were a more relevant trigger in men (Table 4). These results could indicate that women have a different coping with stress than men, whereas men are more exposed to physical/mechanical exertion. We speculate that women have a better self-perception enabling them to recognize prodromal symptoms and trigger factors better than men.

\section{Frequency and localization of angioedema}

Regardless of gender, the abdomen was the most affected body part, followed by the extremities. In other cohorts this was the opposite $[13,20]$. Compared to men, women suffered from more attacks to all localizations except the genitals and larynx. The constitutional exposure of

Table 7 Prophylaxis with danazol and comparison of location-related symptoms between women and men in 2012

\begin{tabular}{|c|c|c|c|c|c|c|c|c|c|c|}
\hline \multirow{2}{*}{$\begin{array}{l}\text { Location } \\
\text { of attacks }\end{array}$} & \multirow[t]{2}{*}{ All } & \multicolumn{3}{|l|}{ Women } & \multirow{2}{*}{$\begin{array}{l}\text { no prophylaxis vs. } \\
\text { Danazol } \\
\text { p-values }\end{array}$} & \multicolumn{3}{|l|}{ Men } & \multirow{2}{*}{$\begin{array}{l}\text { no prophylaxis vs. } \\
\text { Danazol } \\
\text { p-values }\end{array}$} & \multirow{2}{*}{$\begin{array}{l}\text { women vs. } \\
\text { men } \\
p \text {-values }\end{array}$} \\
\hline & & All & $\begin{array}{l}\text { No } \\
\text { prophylaxis }\end{array}$ & Danazol & & All & $\begin{array}{l}\text { No } \\
\text { prophylaxis }\end{array}$ & Danazol & & \\
\hline & 104 & 57 & 31 & 13 & & 47 & 28 & 13 & & \\
\hline abdomen & 68 (65 \%) & $40(70 \%)$ & 24 (77 \%) & $\begin{array}{l}6 \\
(46 \%)\end{array}$ & $p=0.042$ & $\begin{array}{l}28 \\
(59 \%)\end{array}$ & 15 (53\%) & $\begin{array}{l}9 \\
(69 \%)\end{array}$ & $p=0.344$ & $p=0.063$ \\
\hline extremities & 61 (59\%) & $34(60 \%)$ & 20 (64 \%) & $\begin{array}{l}5 \\
(38 \%)\end{array}$ & $p=0.111$ & $\begin{array}{l}27 \\
(57 \%)\end{array}$ & 14 (50 \%) & $\begin{array}{l}8 \\
(61 \%)\end{array}$ & $p=0.491$ & $p=0.157$ \\
\hline trunk & $22(21 \%)$ & $15(26 \%)$ & $8(26 \%)$ & $\begin{array}{l}3 \\
(10 \%)\end{array}$ & $p=0.849^{*}$ & $\begin{array}{l}7 \\
(15 \%)\end{array}$ & 4 (14 \%) & 0 & $p=0.288^{*}$ & $p=0.523^{*}$ \\
\hline face & $22(21 \%)$ & $14(24 \%)$ & $8(26 \%)$ & $2(6 \%)$ & $p=0.697^{*}$ & $\begin{array}{l}8 \\
(17 \%)\end{array}$ & 4 (14 \%) & 1 (8 \%) & $p=0.486^{* *}$ & $p=0.709^{* *}$ \\
\hline genitals & $22(21 \%)$ & 11 (19\%) & 8 (26 \%) & 1 (3 \%) & $p=0.242^{*}$ & $\begin{array}{l}11 \\
(23 \%)\end{array}$ & 5 (18\%) & $\begin{array}{l}3 \\
(23 \%)\end{array}$ & $p=0.692^{*}$ & $p=0.586^{*}$ \\
\hline headache & 16 (15 \%) & 11 (19\%) & 4 (13\%) & $\begin{array}{l}3 \\
(10 \%)\end{array}$ & $p=0.404^{*}$ & $\begin{array}{l}5 \\
(11 \%)\end{array}$ & 4 (14 \%) & 0 & $p=0.288^{*}$ & $p=0.509^{*}$ \\
\hline larynx & 16 (15\%) & 9 (16 \%) & 6 (19\%) & 1 (3 \%) & $p=0.654$ & $\begin{array}{l}7 \\
(15 \%)\end{array}$ & 4 (14 \%) & 1 (8 \%) & $p=0.486^{* *}$ & $p=0.700^{* *}$ \\
\hline
\end{tabular}

* Fisher's exact test, ${ }^{* *}$ one-sided

Number of patients who suffered from at least one attack in the individual location in 2012 
Table 8 Comorbidities

\begin{tabular}{|c|c|c|c|c|c|c|c|c|c|}
\hline \multirow[t]{2}{*}{ Co-morbidities } & \multicolumn{3}{|c|}{ All patients } & \multicolumn{3}{|c|}{ Patients without danazol } & \multicolumn{3}{|c|}{ Patients on danazol } \\
\hline & & w & m & & w & m & & w & m \\
\hline All & 104 & 57 & 47 & 78 & 44 & 34 & 26 & 13 & 13 \\
\hline No comorbidities & $7168 \%$ & $3765 \%$ & $3472 \%$ & $5672 \%$ & $3375 \%$ & $2676 \%$ & $1246 \%$ & $431 \%$ & $861 \%$ \\
\hline Comorbidities & $3332 \%$ & $2035 \%$ & $1328 \%$ & $1924 \%$ & $1125 \%$ & $823 \%$ & $1454 \% \%$ & $969 \%$ & $538 \%$ \\
\hline Arterial Hypertension & $2322 \%$ & $1424 \%$ & $919 \%$ & $1114 \%$ & $614 \%$ & $515 \%$ & $1246 \%$ & $861 \%$ & 431 \\
\hline Dyslipidemia & $66 \%$ & $59 \%$ & $12 \%$ & 0 & 0 & 0 & $623 \%$ & $538 \%$ & $12 \%$ \\
\hline DVT & $44 \%$ & $12 \%$ & $36 \%$ & $22 \%$ & 0 & $26 \%$ & $28 \%$ & $12 \%$ & 1 \\
\hline Depression & $44 \%$ & $23 \%$ & $24 \%$ & $22 \%$ & $12 \%$ & $13 \%$ & $28 \%$ & 1 & 1 \\
\hline CHD & $44 \%$ & $35 \%$ & $12 \%$ & $45 \%$ & $37 \%$ & $13 \%$ & 0 & 0 & 0 \\
\hline CVI & $10.9 \%$ & 0 & $12.1 \%$ & 0 & 0 & 0 & $13.8 \%$ & 0 & 1 \\
\hline PAD & $11 \%$ & 0 & $12 \%$ & $11 \%$ & 0 & $12.9 \%$ & 0 & 0 & 0 \\
\hline Diabetes mellitus & $55 \%$ & $47 \%$ & $12 \%$ & $34 \%$ & $24 \%$ & $13 \%$ & $28 \%$ & $215 \%$ & 0 \\
\hline Epilepsy & $11 \%$ & $12 \%$ & 0 & $11 \%$ & $12 \%$ & 0 & 0 & 0 & 0 \\
\hline Schizophrenia & $11 \%$ & 0 & $12 \%$ & 0 & 0 & $13 \%$ & 0 & 0 & 0 \\
\hline Parkinson's disease & $22 \%$ & $23 \%$ & 0 & $11 \%$ & $12 \%$ & 0 & $14 \%$ & 1 & 0 \\
\hline Hypothyroidism & $22 \%$ & $12 \%$ & $12 \%$ & $1 \%$ & $12 \%$ & 0 & $14 \%$ & 0 & 1 \\
\hline COPD/Asthma & $22 \%$ & $23 \%$ & 0 & $22 \%$ & $24 \%$ & 0 & 0 & 0 & 0 \\
\hline Osteoporosis & $22 \%$ & $23 \%$ & 0 & $22 \%$ & $24 \%$ & 0 & 0 & 0 & 0 \\
\hline
\end{tabular}

CHD Coronary heart disease, CVI Cerebrovascular Insult, DVT deep venous thrombosis, PAD peripheral artery disease

genitals could explain why angioedema of this region occur more often in male. In order to identify the reasons for the more common laryngeal swellings in men, one can only guess that pharyngeal/laryngeal irritation by airway infections [19], snoring [21] or smoking [22] are relevant triggers.

\section{Gender related efficacy of danazol prophylaxis}

Prophylactic danazol therapy is widely used in HAEtreatment. Its efficacy is well known, as are its side effects [23]. Danazol, on one hand, stimulates the liver to synthesize C1-INH and enhances the expression of C1INH mRNA in peripheral blood mononuclear cells [24]. On the other hand, as a weak androgen, danazol has an antigonadotropic effect and inhibits ovarial estrogen production. If the daily dosage does not exceed $200 \mathrm{mg}$ and treatment is closely monitored for possible side effects such as virilisation, hepatic diseases, arterial hypertension and dyslipidemia, it is a reasonable therapy for adult patients and those women who are neither pregnant nor breast-feeding [15, 25-29]. Development of liver cell adenomas or even hepatocellular carcinomas on long term therapy with danazol are uncommon [30, 31].

Comparing danazol prophylaxis between women and men, it seems that the drug has a better and different effect in women than in men.

Women on danazol suffered from fewer attacks to the abdomen and extremities than men on danazol (Table 7).
It can be assumed that the hormonal modulating effect of danazol with suppression of gonadotropin and reduced estrogen production leads to a decreased stimulation of the contact activation pathway and consecutively to a decreased bradykinin production, which is essential in this prophylactic therapy. The high therapeutic efficacy of danazol in women could also explain why an important part of women (23\%) are on danazol prophylaxis despite a higher frequency of side effects.

\section{Comorbidities}

In this cohort, patients on danazol suffer from more comorbidities (54\%) compared to those without prophylaxis $(24 \%)$. Women on danazol were more affected by comorbidities than men on danazol (69\% vs $38 \%$ ). Danazol treatment showed a clear association with Dyslipidemia.

\section{Therapy of attacks}

Attacks were treated with pd C1-INH in $55 \%$ of cases. Only few used Icatibant. The reason for this might be that Icatibant has not been on the Swiss market long enough (since 2009) and patients require a certain time to gain trust in new therapies. On the other hand, therapy with C1-INH seems to be more sustainable for patients with frequent attacks.

About two-thirds of patients using $\mathrm{C} 1$-INH practice home treatment after being carefully instructed in a HAE- center [32]. Offering home therapy and self- 
treatment to all HAE patients is a goal worth striving for. It's the best way of optimizing treatment for a disorder with highly individual symptoms, improving quality of life with fewer and less severe attacks. As they do not require medical facilities, their medicare costs also decrease. Against doctors' recommendation, $14 \%$ of acute attacks were not treated at all. This is most likely because of an attitude that attacks that do not seem to be life-threatening do not require treatment.

\section{Conclusion}

The aim in treating HAE-affected people is to minimize their swelling episodes in the best possible manner with the limited therapeutic options. First and foremost, the treating physician should be aware that symptoms vary across individuals and that women suffer from a more severe disease activity than men. The therapy plan must include careful training in self-perception to recognize prodromal symptoms and trigger factors and a training in administering self-therapy for acute swelling episodes. This should lead to lifestyle adaption by avoiding triggers as much as possible and individualizing the treatment with early start of therapy according to prodromal symptoms and acute attacks. This gives the patient independency and more self-responsibility. Danazol, as an efficient prophylaxis, requires close supervision of side effects. Women seem to have a better benefit from danazol than men, but also suffer from more side effects. But this assumption should be confirmed in a prospective study comparing genders and frequency of angioedema before and with danazol. New therapies which selectively influence the hormonal estrogen balance could open new therapeutic options mainly for women and maybe also for men.

\section{Abbreviations \\ HAE: hereditary angioedema; pdC1-INH: plasma derived C1-Inhibitor;} FXII: factor XII; TA: tranexamic acid.

\section{Competing interests}

The authors declare that they have no competing interests.

\section{Authors' contributions}

US: carried out concept and design of the study, accumulation of data; analysis and interpretation of the data, performed statistical analysis, writing/ critical revision of the manuscript. CW: analysis and interpretation of the data; writing/critical revision of the manuscript. KS: analysis and interpretation of the data; writing/critical revision of the manuscript. AH: concept and design of the study; analysis and interpretation of the data; writing/critical revision of the manuscript. PS: analysis and interpretation of the data; writing/critical revision of the manuscript. WW: concept and design of the study; accumulation of data, analysis and interpretation of the data; writing/critical revision of the manuscript. All authors read and approved the final manuscript.

\section{Author details}

'Division of Clinical Immunology, University Hospital Zurich, Zurich, Switzerland. ${ }^{2}$ Allergy Unit, Department of Dermatology, University Hospital Zurich, Zurich, Switzerland. ${ }^{3}$ Division of Allergology, University Clinic of Rheumatology, Immunology and Allergology, Inselspital Bern, Bern,
Switzerland. ${ }^{4}$ Allergy Unit, Department of Dermatology, University Hospital Basel, Basel, Switzerland. ${ }^{5}$ Division of Heamatology and Central Heamatology Laboratory, Department of Internal Medicine, Kantonsspital Lucerne and University of Berne, Berne, Switzerland.

Received: 19 January 2016 Accepted: 12 April 2016

Published online: 21 April 2016

\section{References}

1. Agostoni A, Cicardi M. Hereditary and acquired C1-inhibitor deficiency: biological and clinical characteristics in 235 patients. Med (Baltimore). 1992; 71(4):206-15.

2. Bork K, Hardt J, Schicketanz KH, Ressel N. Clinical studies of sudden upper airway obstruction in patients with hereditary angio-oedema due to C1 esterase inhibitor deficiency. Arch Inern Med. 2003;163:1229-35.

3. Cicardi M, Aberer W, Banerji A, Bas M, Bernstein JA, Bork K, Caballero T, Farkas H, Grumach A, Kaplan AP, Riedl MA, Triggiani M, Zanichelli A, Zuraw $B$, on behalf of HAWK, under the patronage of EAACI (European Academy of Allergy and Clinical Immunology). Classification, diagnosis, and approach to treatment for angioedema: consensus report from the Hereditary Angioedema International Working Group. Allergy. 2014;69:602-16.

4. Zuraw BL. Clinical practice. Hereditary angioedema. N Engl J Med. 2008; 359(10):1027-36. doi:10.1056/NEJMcp0803977.

5. Bork K. Hereditary angioedema with normal C1 inhibitor. Immunol Allergy Clin North Am. 2013;33(4):457-70. doi:10.1016/j.iac.2013.07.002.

6. Bygum A. Hereditary angio-oedema in Denmark a nationwide survey. Br J Dermatol. 2009;161:1153-8.

7. Roche O, Blanch A, Caballero T, Sastre N, Callejo D, López-Trascasa M. Hereditary angioedema due to $C 1$ inhibitor deficiency: patient registry and approach to the prevalence in Spain. Ann Allergy Asthma Immunol. 2005; 94(4):498-503

8. Jolles S, Williams P, Carne E, Mian H, Huissoon A, Wong G, et al. A UK national audit of hereditary and acquired angioedema. Clin Exp Immunol. 2014;175(1):59-67. doi:10.1111/cei.12159.

9. Zanichelli A, Arcoleo F, Varca MP, Borrelli P, Bova M, Cancian M, et al. A nationwide survey of hereditary angioedema due to $C 1$ inhibitor deficiency in Italy. Orphanet J Rare Dis. 2015;10:11. doi:10.1186/s13023-015-0233-x.

10. Streuli R, Grob P. Study of a large family with hereditary angioneurotic edema. Schweiz Med Wochenschr. 1975;105(43):1382-7.

11. Wais-Nocker B, Steiner U, Spath P, Wuillemin WA. [Clinical facets of hereditary angioedema among Swiss patients]. Praxis (Bern 1994). 2010; 99(19):1135-41.

12. Winnewisser J, Rossi M, Spath P, Burgi H. Type I hereditary angio-oedema. Variability of clinical presentation and course within two large kindreds. J Intern Med. 1997;241(1):39-46.

13. Bork K, Meng G, Staubach P, Hardt J. Hereditary angioedema: new findings concerning symptoms, affected organs, and course. Am J Med. 2006;119(3): 267-74. doi:10.1016/j.amjmed.2005.09.064

14. The Helsinki Declaration of the World Medical Association (WMA). Ethical principles of medical research involving human subjects. Pol Merkur Lekarski. 2014;36(215):298-301.

15. Craig T, Aygoren-Pursun E, Bork K, Bowen T, Boysen H, Farkas $H$, et al. WAO Guideline for the Management of Hereditary Angioedema. World Allergy Organ J. 2012;5(12):182-99. doi:10.1097/WOX.0b013e318279affa.

16. Kreuz W, Martinez-Saguer I, Aygoren-Pursun E, Rusicke E, Heller C, Klingebiel T. C1-inhibitor concentrate for individual replacement therapy in patients with severe hereditary angioedema refractory to danazol prophylaxis. Transfusion. 2009;49(9):1987-95. doi:10.1111/j.1537-2995.2009.02230.x.

17. Visy B, Fust G, Varga L, Szendei G, Takacs E, Karadi I, et al. Sex hormones in hereditary angioneurotic oedema. Clin Endocrinol (Oxf). 2004;60(4):508-15. doi:10.1111/j.1365-2265.2004.02009.x.

18. Maurer M, Aberer W, Bouillet L, Caballero T, Fabien V, Kanny G, et al. Hereditary angioedema attacks resolve faster and are shorter after early icatibant treatment. PLoS One. 2013;8(2), e53773. doi:10.1371/journal.pone. 0053773.

19. Zotter Z, Csuka D, Szabo E, Czaller I, Nebenfuhrer Z, Temesszentandrasi G, et al. The influence of trigger factors on hereditary angioedema due to C1-inhibitor deficiency. Orphanet J Rare Dis. 2014;9:44. doi:10.1186/17501172-9-44.

20. Zanichelli A, Vacchini R, Badini M, Penna V, Cicardi M. Standard care impact on angioedema because of hereditary C1 inhibitor deficiency: a 21-month 
prospective study in a cohort of 103 patients. Allergy. 2011;66(2):192-6. doi:10.1111/j.1398-9995.2010.02433.x.

21. Bork K, Koch P. Episodes of severe dyspnea caused by snoring-induced recurrent edema of the soft palate in hereditary angioedema. J Am Acad Dermatol. 2001;45(6):968-9.

22. Sanli A, Bekmez E, Yildiz G, Atalay Erdogan B, Baki Yilmaz H, et al. Relationship between smoking and otorhinolaryngological symptoms. Kulak Burun Bogaz Ihtis Derg. 2016;26(1):28-33.

23. Fust G, Farkas H, Csuka D, Varga L, Bork K. Long-term efficacy of danazol treatment in hereditary angioedema. Eur J Clin Invest. 2011;41(3):256-62. doi:10.1111/j.1365-2362.2010.02402.x.

24. Pappalardo E, Zingale LC, Cicardi M. Increased expression of C1-inhibitor mRNA in patients with hereditary angioedema treated with Danazol. Immunol Lett. 2003;86(3):271-6.

25. Birjmohun RS, Kees Hovingh G, Stroes ES, Hofstra JJ, Dallinga-Thie GM, Meijers JC, et al. Effects of short-term and long-term danazol treatment on lipoproteins, coagulation, and progression of atherosclerosis: two clinical trials in healthy volunteers and patients with hereditary angioedema. Clin Ther. 2008;30(12):2314-23. doi:10.1016/j.clinthera.2008.12.021.

26. Bork K, Bygum A, Hardt J. Benefits and risks of danazol in hereditary angioedema: a long-term survey of 118 patients. Ann Allergy Asthma Immunol. 2008:100(2):153-61. doi:10.1016/S1081-1206(10)60424-3.

27. Cugno M, Cicardi M, Bottasso B, Coppola R, Paonessa R, Mannucci PM, et al. Activation of the coagulation cascade in C1-inhibitor deficiencies. Blood. 1997:89(9):3213-8.

28. Farkas $H$, Czaller I, Csuka D, Vas A, Valentin $S$, Varga $L$, et al. The effect of long-term danazol prophylaxis on liver function in hereditary angioedema-a longitudinal study. Eur J Clin Pharmacol. 2010;66(4):419-26. doi:10.1007/ s00228-009-0771-Z.

29. Zotter Z, Veszeli N, Csuka D, Varga L, Farkas H. Frequency of the virilising effects of attenuated androgens reported by women with hereditary angioedema. Orphanet J Rare Dis. 2014;9:205. doi:10.1186/ s13023-014-0205-6.

30. Bork K, Pitton M, Harten P, Koch P. Hepatocellular adenomas in patients taking danazol for hereditary angio-oedema. Lancet. 1999;353(9158):1066-7. doi:10.1016/S0140-6736(99)00110-5.

31. Rahal S, Gilabert M, Ries P, Oziel-Taieb S, Dermeche S, Raoul J Hepatocellular carcinoma in a noncirrhotic liver after long-term use of danazol for hereditary angioedema. Case Rep Oncol. 2014;7(3):825-7. doi:10. 1159/000370106

32. Wuillemin WA. Therapeutic agents for hereditary angioedema. N Engl J Med. 2011;364(1):84-5. doi:10.1056/NEJMc1010085\#SA1. author reply 5-6.

\section{Submit your next manuscript to BioMed Central and we will help you at every step:}

- We accept pre-submission inquiries

- Our selector tool helps you to find the most relevant journal

- We provide round the clock customer support

- Convenient online submission

- Thorough peer review

- Inclusion in PubMed and all major indexing services

- Maximum visibility for your research

Submit your manuscript at www.biomedcentral.com/submit
Biomed Central 